\title{
Una aproximación al estudio del infoentretenimiento en Internet: origen, desarrollo y perspectivas futuras
}

Salomé Berrocal Gonzalo Universidad de Valladolid

Marta Redondo García

Universidad de Valladolid

Eva Campos Domínguez

Universidad de Valladolid

\section{Palabras clave}

Infoentretenimiento, televisión, Internet, interactividad, comunicación política

\section{Resumen}

El fenómeno del infoentretenimiento es señalado, por algunos autores, como la «mega tendencia» más acusada del periodismo actual (Prado, 2003:178-186). Los contenidos televisivos, radiofónicos e incluso los de la prensa seria buscan cada vez más resultar entretenidos, lo que lleva a despreciar o dedicar menos espacio a los tradicionales temas de interés público para buscar nuevos asuntos que despierten la curiosidad del receptor. Partiendo de esta premisa, esta investigación se basa en una revisión cualitativa de la literatura publicada en el ámbito nacional e internacional hasta la fecha sobre el infoentretenimiento político en Internet, con el objetivo de conocer cómo y qué se investiga en nuestro país sobre este fenómeno novedoso de la actividad comunicacional. Los resultados muestran que, a pesar de que en los últimos años han ido surgiendo investigaciones, dentro y fuera de España, aún son precisos nuevos estudios que exploren la forma, contenido y consecuencias del infoentretenimiento político en la red. El objetivo de este estudio es, por tanto, establecer un estado del la cuestión, conocer qué dimensión investigadora tiene este fenómeno en la academia española e intentar definir nuevas líneas de estudio y exploración futura de un fenómeno que, según apunta la propia literatura, continuará en progresión, tanto en Internet como en los formatos tradicionales. 


\title{
An Approximation for the Study of Infotainment on the Internet: Origin, Development and Future Perspectives
}

\section{Keywords}

Infotainment, television, Internet, interactivity, political communication

\begin{abstract}
Infotainment is considered as the dominant trend in journalism and communication (Prado, 2003:178-186). Television, radio and even serious press increasingly seek to entertain. This phenomenon leads to despising or dedicating less time to traditional topics of public interest to look for new matters that wake the curiosity of the audience. Based on this argument, this investigation develops a qualitative review of the literature published in national and international context on political infotainment on the Internet in order to update knowledge on infotainment. The results show that, in spite of the fact that lately investigations have been arising, inside and out of Spain, still are needed new studies that explore the form, content and consequences of political infotainment on the network. The aim of this study is, therefore, to know what investigative dimension has this phenomenon in the Spanish academy and to try to define new lines of study and future exploration of a phenomenon which is increasingly importantly on the Internet and in traditional media as well. Some suggested lines of research are: the relationship between infotainment and interactivity, the use of infotainment in search of economic profit from new media or the review of the classic uses and the gratifications theories applied to the information on the Internet.
\end{abstract}

\footnotetext{
Autoras

Salomé Berrocal Gonzalo [salomeb@hmca.uva.es] es profesora titular de Periodismo en la Universidad de Valladolid, donde imparte la disciplina de Comunicación Política. Sus estudios y publicaciones están relacionadas con sus dos líneas de investigación: la Comunicación Política y el Análisis de los Efectos que producen los Medios de Comunicación en la Opinión Pública. En los últimos años destacan sus estudios sobre el fenómeno del infoentretenimiento político.

Marta Redondo García [marta.redondo@hmca.uva.es] es doctora en Periodismo por la Universidad de Valladolid es profesora de la Licenciatura y el Grado en Periodismo en esa Universidad. Ha trabajado en diversos medios de comunicación: Vía Digital, Antena 3, Televisión Española como redactora y presentadora de espacios informativos. Ha publicado diversos artículos de investigación en torno al sensacionalismo y el infoentretenimiento.
} 
Eva Campos Domínguez [eva.campos@hmca.uva.es] es profesora contratada doctor de comunicación y nuevas tecnologías en la Universidad de Valladolid, doctora en Ciencias de la Información por la Universidad Complutense de Madrid, Premio Extraordinario de Doctorado (2009), Premio Joven de Comunicación (FGUCM, 2007) y especialista en Tecnologías y Comunicación Multimedia. Cuenta con varias publicaciones sobre la ciberdemocracia y la comunicación política en Internet. 


\section{Introducción: análisis de un fenómeno comunicativo en expansión}

Desde los años 80 distintos estudios, tanto internacionales como nacionales, han dado cuenta de una variación en la naturaleza de la información televisiva consistente en combinar la información con el entretenimiento. Para referirse a este proceso comenzó a utilizarse el término anglosajón infotainment y su traducción castellana infoentretenimiento, un vocablo que pone de manifiesto la tendencia en el periodismo -principalmente televisivo-, a difuminar las fronteras entre aspiraciones tradicionalmente distantes e incluso divergentes. La expresión deja clara la evolución hacia la hibridación que vive el mensaje audiovisual donde información y diversión aparecen unidas.

El infoentretenimiento se manifiesta, en estos trabajos, en dos corrientes paralelas dentro de los contenidos televisivos: por un lado, en la incorporación de noticias ligeras o menores dentro de los informativos tradicionales, por otro, en la tendencia a abordar asuntos de información seria pertenecientes al debate público dentro de programas y formatos destinados prioritariamente a la distracción del espectador. Así, por ejemplo, talk-shows donde se debaten cuestiones políticas junto a asuntos del corazón de los famosos o programas humorísticos cuyos protagonistas son personajes de la política o la economía.

Pero el infoentretenimiento televisivo es, además de temático, estilístico de modo que no sólo implica una elección noticiosa sino también un tratamiento de esa información caracterizado por: un dominio de mensajes simples, emotivos y sensacionalistas (Labio Bernal, 2008); una presentación de la información seria «con una visión frívola, uniforme y residual» (Cebrián y Berrocal, 2010: 43); una fragmentación de la actualidad en un mosaico de hechos descontextualizados (Ramonet, 1999) o la incorporación de «sentimientos personales, tintes dramáticos o ingredientes cómicos» con un dominio de la personalización de la información (Berrocal, Campos y Redondo, 2012: 3). Además, el infoentretenimiento abunda en unos estilos de edición que buscan añadir espectacularidad a lo grabado, incrementando el ritmo en la sucesión de los planos, introduciendo dramatizaciones, música ambiente, efectos de sonido, planos muy cortos e imágenes a cámara lenta para dotarlas de mayor intensidad y empleando un estilo de presentación enfático (Lozano, 2004).

Las investigaciones consultadas identifican los motivos de la aparición del infoentretenimiento en las televisiones occidentales coincidente con la expansión de la televisión privada frente a la pública y, derivado de ello, la necesidad de desarrollar estrategias para atraer a una audiencia masiva en un mercado altamente competitivo. El condicionante económico, pues, se sitúa en el origen del fenómeno. Un medio como la televisión generalista con altos costes de producción y dependiente casi por completo de la publicidad para financiarse necesita ser masivo para resultar rentable, por tanto, debe rebajar las aspiraciones en cuanto a la temática y complejidad de su mensaje puesto que una elevación excesiva podría resultar disuasoria para el gran público: «cualquiera puede tolerar 
un producto menos sofisticado de lo que le gustaría; en cambio, si el contenido supera su capacidad de comprensión se produce un rechazo completo» (Sánchez-Tabernero, 2008: 85).

Esa necesidad de propiciar un producto verdaderamente popular provoca que se seleccionen determinados argumentos informativos que, pese a carecer de relevancia pública, sí despiertan la atención y la curiosidad de los receptores. También que se privilegien ciertos tratamientos ligeros que resultan atractivos y que, en consecuencia, facilitan la digestión de la información. Un proceso que es más evidente en el medio televisivo aunque no sea exclusivo de él. A pesar de que la mayoría de estudios sobre infoentretenimiento se han centrado en la televisión, lo cierto es que el término hace referencia a una tendencia periodística hacia la representación de la realidad en clave espectacular que puede producirse en cualquier medio de comunicación. El proceso sería el que describe García Avilés: «los contenidos y las formas narrativas se seleccionan teniendo como criterio supremo el impacto que puedan causar en la audiencia, en lugar de la capacidad para suministrar información relevante, de la forma más rigurosa posible» (2007: 51). Un fenómeno que hunde sus raíces en el sensacionalismo informativo y enlaza así con la primera generación de prensa popular destinada más al pasatiempo que a la información.

\section{Metodología}

Tomando en cuenta el escenario descrito, esta investigación se centra en una exploración de la literatura existente sobre el infoentretenimiento en Internet y realiza un estudio cualitativo de la bibliografía publicada hasta la fecha en el ámbito académico español. Este análisis principal se complementa con otras publicaciones internacionales, principalmente del ámbito anglosajón. El instrumento de análisis empleado fueron fichas de análisis bibliométrico, con ítems de respuesta abierta, que tenían como finalidad definir el infoentretenimiento en Internet y conocer sus principales características en nuestro campo español.

Por tanto, el artículo parte de la fijación del concepto de infoentretenimiento para explicar el contexto en el que este fenómeno informativo se ha desarrollado en el medio televisivo y constatar su capacidad para difundirse también a otros medios de comunicación.

\section{El infoentretenimiento televisivo como objeto de estudio}

Antes de que se acuñase y extendiese el término infoentretenimiento, ya existía un interés académico por analizar la capacidad de la televisión para convertir todo aquello que pasa por ella en espectáculo. Bien en el ámbito internacional -Neil Postman (1985), Furio Colombo (1997), Giovanni Sartori (1998), Pierre Bordieu (1997) o Ignacio Ramonet (1999), entre otros-, como en el nacional 
-González Requena (1988) o Sánchez Noriega (1997) por ejemplo-, señalaban los riesgos de un medio de comunicación cuya principal pretensión fuese la diversión por encima de otras consideraciones. Sartori llegaba a denunciar: «Los noticiarios de nuestra televisión actual emplean 20 minutos de su media hora de duración en saturarnos de trivialidades y de noticias que sólo existen porque se deciden y se inventan en la rebotica de los noticiarios. ¿Información? Sí, también la noticia de la muerte de una gallina aplastada por un derrumbamiento se puede llamar información. Pero nunca será digna de mención» (Sartori, 1998: 83).

El neologismo infotainment comenzó a emplearse en los estudios norteamericanos como un cliché para aludir a los males de la televisión de ese país aglutinados en una tendencia que pronto se haría global. La preocupación académica alumbró numerosos trabajos centrados, en un primer momento, en evidenciar su presencia y crecimiento dentro de los programas informativos de las televisiones occidentales.

Holtz-Bacha y Norris (2001), en su estudio sobre la programación en los canales públicos europeos, concluyen que los noticiarios cada vez incorporan a su escaleta más noticias de interés humano mientras que reducen o excluyen las más densas de política nacional e internacional. Anderson (2004) destaca la presencia en los informativos estadounidenses de lo que denomina entertainmentpseudo news destinadas a la distracción del espectador pero con escaso valor de interés público. En Bélgica, Canninga (1994) y en Dinamarca, Powers et al (1994) evidencian un incremento de las noticias menores e informaciones sobre sucesos en los informativos de esos países. John Langer (2000), utilizando el término tabloide en sinonimia con infoentretenimiento, analiza lo que denomina las «otras noticias» (noticias blandas) de los cuatro principales informativos de Melbourne para constatar que su presencia va en aumento. En Reino Unido, Franklin (1997) hace una crítica global del fenómeno viendo en él una señal del «apocalipsis» del periodismo donde el entretenimiento acaba por vencer a la información: «el interés humano ha suplantado al interés público, el juicio mesurado ha sucumbido al sensacionalismo, lo trivial ha triunfado sobre la información de peso, las relaciones íntimas de las celebrities de las series televisivas, el mundo del deporte o los asuntos de la familia real son considerados informativamente más valiosos que el reporterismo sobre materias significativas y acontecimientos de consecuencia internacional [...] el infoentretenimiento es rampante» (1997: 4).

En España, García Avilés realiza un ambicioso análisis comparativo de los informativos líderes de audiencia de la Unión Europea. Entre sus conclusiones, destaca la tendencia general a volverse más homogéneos para adaptarse a un «mínimo común denominador capaz de atraer el mayor número posible de espectadores» (2007: 59). También Ortells (2009) —más limitado su campo de aplicación puesto que se centra únicamente en el estudio de los informativos de la cadena de televisión Cuatro-, evidencia la introducción en ellos no sólo de temáticas menores sino de características estilísticas propias de los géneros de 
entretenimiento e incluso de ficción, como la utilización de música, el empleo de efectos y transiciones exagerados, la introducción de escenificaciones para incorporar elementos cinematográficos, el incremento de la personalización y la emotividad en el enfoque de las noticias o la abundancia de conexiones en directo sin otra justificación que realizar un alarde técnico aportando intensidad al discurso periodístico.

Una vez confirmada su existencia y vigor, los trabajos más importantes que han profundizado en el estudio del infoentretenimiento se sitúan en el campo de la comunicación política y abordan de manera relevante el análisis de la presencia de asuntos políticos en programas de info-show y las consecuencias electorales de la expansión del fenómeno. Buena parte de los autores interpreta que una sociedad en la que los ciudadanos estén deficientemente informados, como se deriva de un ecosistema mediático en que domine el infoentretenimiento, resulta altamente manipulable. Incluso, se ha llegado a ver en esta manera de informar, una amenaza para el sistema democrático. Los numerosos estudiosos que mantienen esta postura - Blumler (1992), Prior (2003, 2005, 2007), Moy, Xenos y Hess (2005), entre otros - entienden que el infoentretenimiento supone una degradación de la información política que impide que los ciudadanos capten la realidad con el rigor preciso para tomar decisiones fundamentadas. Así, Sparks y Tulloch (2000) consideran que si los ciudadanos no acceden a las noticias esenciales que precisan para ejercer sus derechos cívicos - dado que en los medios dominan las informaciones más ligeras-, la democracia que reside en la voluntad popular acabará por banalizarse. Delli Carpini y Williams, en su examen de la reacción de los medios ante el caso Clinton-Lewinsky, señalan que, en esa primera gran manifestación del infoentretenimiento en Estados Unidos, la política nacional se redujo a «un espectáculo para el espectador, a ratos divertido, a veces melodramático pero raramente relevante» (2001: 178).

Sin embargo, hay que señalar que esta valoración del infoentretenimiento como un proceso informativo esencialmente perjudicial no es unánime. Autores como Grabe et al (2000) demostraron que una noticia ofrecida desde técnicas de infoentretenimiento captaba mejor la atención de la audiencia que la misma información presentada de una forma tradicional. Brants (1998), Baum (2002, 2003a, 2003b, 2005, 2006), Stockwell (2004) o, más recientemente, Taniguchi (2011) consideran que los riesgos que supone abordar cuestiones políticas en programas de info-show son menores y que incluso tiene ventajas como la de conseguir popularizar la información política en sectores poco proclives a interesarse por ella. Una tesis también confirmada empíricamente en España por Ferré y Gayá (2009) que, tras analizar la percepción de la política por parte de los espectadores del programa humorístico Polònia de TV3, comprobaron que aquellos espectadores que menos información política consumían habitualmente era para quienes el programa suponía una fuente de información más importante e incluso que el espacio servía para aumentar su atención general por los asuntos políticos. 
Dentro de los estudios españoles sobre infoentretenimiento televisivo, cabe señalar también el análisis del tratamiento de asuntos y personajes políticos en programas de info-show y la influencia que este estilo de transmitir información política puede tener sobre la ciudadanía, abordados por Berrocal et al (2003), Carpio (2009), Berrocal y Cebrián (2009), Valhondo (2011), Sampedro y Valhondo (2012) o el ya mencionado de Ferré y Gayá (2009).

Sin embargo, a pesar de la importancia indudable del fenómeno, el desarrollo del tema resulta insuficiente en España, más si tenemos en cuenta el progreso que los estudios sobre infoentretenimiento están teniendo en el ámbito anglosajón.

\section{La investigación del infoentretenimiento en la red}

Internet se constituye como un poderoso espacio de albergar información. Tal y como han venido señalando diferentes autores, la digitalización de los contenidos hace sencillo su almacenaje y distribución sea cual sea su origen, al tiempo que facilita su consumo en cualquier tiempo y lugar a través de dispositivos muy variados, la mayoría móviles y de uso cotidiano.

Estas cualidades hacen de Internet un espacio virtual de capacidad inmensa que se alimenta de forma constante de todo tipo de informaciones y opiniones sobre asuntos del debate público, pero también de anécdotas, frivolidades, hechos triviales o historias que apelan al morbo o al voyerismo de los internautas, de forma que podríamos considerar que la red se convierte, además de en un medio informativo, en un medio para la socialización, la diversión y el entretenimiento.

Desde los estudios de periodística, las investigaciones sobre la red parecen centradas en este momento en explorar las posibilidades tecnológicas para la edición, elaboración y difusión de información; la participación política de los ciudadanos a través de lo que se ha dado en llamar ciberdemocracia, el papel de los periodistas como catalizadores de la información o la convergencia de los distintos medios y soportes, afrontando en menor medida análisis de contenido más tradicionales y también difíciles de abarcar dada la ingente cantidad de información y datos que la red facilita.

En cuanto a la presencia de infoentretenimiento en la red, la mayoría de las investigaciones - tanto dentro como fuera de España- se han concentrado en estudiar esta tendencia en los contenidos políticos difundidos en Internet, analizando, por ejemplo, los vídeos del portal YouTube, la comunidad de vídeos online más popular del mundo. En esta línea se enmarcan los trabajos de Tyron (2008) y Towner y Dulio (2011) sobre la influencia de los vídeos de YouTube en las elecciones presidenciales estadounidenses de 2008.

En España, algunos de los últimos trabajos (Berrocal y Campos, 2012 y Berrocal, Campos y Redondo, 2012) han analizado la presencia de los principales líderes políticos tanto occidentales como españoles (Barack Obama, Nicolás Sarkozy, 
Silvio Berlusconi, Gordon Brown, José Luis Rodríguez Zapatero, Mariano Rajoy, Rosa Díez y Gaspar Llamazares) en los vídeos más reproducidos en YouTube, concluyendo que los vídeos más vistos de estos protagonistas corresponden precisamente al género del infoentretenimiento, como género transferido del medio televisivo a la red.

A pesar de la escasez de estudios, parece evidente que esta línea investigadora en torno al infoentretenimiento dentro de los contenidos de Internet ha de registrar un enorme desarrollo en los próximos años, dada la importancia que adquiere el fenómeno en la red: «No hay más que ver cómo en cualquier web siempre las noticias más visitadas pertenecen a la categoría del infoentretenimiento en la mayor parte de los casos...La sociedad actual no quiere que el espejo le devuelva una imagen de sus miserias, de sus problemas, sino que desea una imagen más amable» (Díaz Arias, 2010).

Por eso es preciso, además de constatar las posibilidades de análisis futuros, apuntar algunas de las líneas de investigación que cabe pensar que surgirán en los próximos años — siguiendo el panorama internacional-, varias de ellas en continuidad con paradigmas clásicos de la investigación en comunicación.

\subsection{Relación entre infoentretenimiento e interactividad}

La interactividad es una de las características más distintivas de Internet. Los investigadores han venido estudiando la interactividad que favorece las relaciones entre los distintos actores de la comunicación tanto de forma vertical - en una doble dirección: de emisor a receptor y de receptor a emisor-, como horizontal - entre los mismos receptores-. Precisamente es ese potencial interactivo el que ha originado un cambio en las audiencias que ahora «no sólo reaccionan ante los medios, sino que también, participan de diversas formas en el proceso comunicativo aportando opiniones (foros, encuentras, chats...) y produciendo contenidos (textos, fotos, vídeos...)» (Cabrera, 2009: 167-168), dando lugar a una «audiencia creativa», en palabras de Castells (2010).

Por eso, a diferencia de los medios tradicionales, la oferta de Internet no se confecciona exclusivamente con la agenda de los medios presentes en ella sino también con las aportaciones de todo tipo de organizaciones y millones de ciudadanos que conjuntamente construyen lo que podríamos denominar una «macroagenda global». De este modo, las decisiones que profesionalmente toman los medios en torno a la elección y jerarquía de los asuntos noticiosos pierden fuerza en el discurso del ciberespacio que genera «un nuevo entorno en el que hay que entender el consumo como un proceso colectivo, una dinámica cultural» (Roca, 2009: 102).

En Internet son las preferencias del público las que encumbran las noticias más leídas, las fotos más vistas, los vídeos más reproducidos, los audios más escuchados, los mensajes más compartidos y todo ello ajeno a las consideraciones profe- 
sionales que rigen el trabajo periodístico. En la toma de decisiones de la mayoría de los usuarios no pesan necesariamente cuestiones como el rigor, el cotejo de fuentes, la separación de géneros, la diferenciación entre información y opinión, publicidad o entretenimiento. El ciudadano sanciona o premia reproduciendo, votando, difundiendo de forma viral, aquellas noticias que despiertan más su interés sin otras consideraciones. Por ese motivo, buena parte de los contenidos más populares se incardina dentro del género del infoentretenimiento.

Junto a ello, se genera el fenómeno sociológico descrito por Noelle-Neuman de la espiral del silencio: «las personas observan constantemente su entorno muy de cerca. Tratan de averiguar qué opiniones y modos de comportamiento son frecuentes, y de saber las opiniones y modos de comportamiento que son cada vez más populares» (2010: 302). Siguiendo este argumento, a mayor número de usuarios que han consumido un contenido en Internet es probable una mayor difusión —que estos harán de él- y también un mayor interés suscitado entre el público que aún no lo ha presenciado, de forma que el gusto mayoritario se retroalimenta para favorecer que aquellos productos populares lo sean aún más, poniéndose en marcha el mecanismo que construye lo masivo.

Constatado este proceso resulta necesario realizar una actualización, dentro de la tradicional teoría de la agenda setting, sobre la fijación de la agenda en Internet y la influencia que el gusto mayoritario tiene para el receptor a la hora de consumir contenidos en red; algo ya adelantado por Chaffee y Metzger (2001) que llegaban a cambiar los términos del esquema tradicional proponiendo que en Internet era el público quien señalaba a los medios los temas que debían tratar.

Las necesarias investigaciones que pueden desarrollarse en este sentido tienen la ventaja de poder aprovecharse de la nueva tecnología que permite conocer el gusto de la audiencia contabilizando el número de visitas o descargas de contenidos, los comentarios generados e, incluso, acceder a información sociológica relevante como la edad o el sexo de los receptores.

\subsection{Infoentretenimiento y búsqueda de la rentabilidad en Internet}

La popularidad del infoentretenimiento también puede ser analizada poniendo el foco en las decisiones que toman las empresas y los profesionales de los medios que operan en Internet.

Las empresas periodísticas y grupos de comunicación que difunden sus productos en la red necesitan - aunque la mayoría no lo logre aún-, tener un volumen de visitas suficiente para asegurar la rentabilidad del medio, dada la (todavía) gratuidad de la mayoría de los contenidos. De hecho, alcanzar un número interesante de visitantes es el reto al que se enfrenta buena parte de los medios digitales. Filloux y Gassée (2008) han calculado que, con los actuales rendimientos de la publicidad (que en 2008 fijaban entre 0,15 y 0,30 euros por usuario único 
al mes), los grandes diarios europeos y norteamericanos necesitarían más de 8 millones de usuarios únicos mensuales para poder mantener una redacción de unas 100 personas y cubrir gastos, algo impensable en estos momentos.

Esta situación genera unas necesidades ante las que los medios pueden reaccionar pasando a cobrar sus informaciones, estableciendo estrategias para incrementar el número de visitantes a sus webs o inventar un nuevo modelo de negocio no encontrado todavía (Castells, 2010). Optar por la segunda posibilidad señalada supone hacer determinadas concesiones en los contenidos. Como ha apuntado Roca, «cuando el servicio es gratuito para el usuario final los medios se ven abocados a la guerra de las audiencias» (2009:103), una situación que guarda claro paralelismo con el momento que alumbró el infoentretenimiento en televisión.

El infoentretenimiento, como contenido de éxito en el gusto masivo, se puede articular como una herramienta clave para popularizar la información como ya apreciaron De Fleur y Ball-Rockeach: «El contenido de entretenimiento que parece más capaz de atraer la atención de una mayor cantidad de los miembros del público es el contenido de bajo gusto. Puesto que el objetivo más esencial del sistema de medios es el lucro económico, el contenido de sexo y violencia, o cualquiera otro que suscite la atención y la mantenga, pasa a ser funcional, en el sentido de que, aunque sea de bajo gusto, lleva una cifra máxima en los volúmenes de público expuesto ante la publicidad comercial» (1993: 185).

Hay estudios iniciados que apuntan a que la opinión de los receptores, expresada a través de secciones como «Lo + visto» o «Lo + leído» de la edición digital de los diarios, tiene influencia en el diseño de sus webs e incluso determina que hagan un seguimiento más puntual de cualquier acontecimiento aparecido en esas secciones que tenga continuidad en el tiempo. Sin duda es necesario un análisis más extendido y exhaustivo de los contenidos de los medios y portales de Internet para confirmar o desechar esta tendencia y comprobar su evolución.

\subsection{Infoentretenimiento y la perspectiva de los usos y consumos de Internet}

El análisis del infoentretenimiento digital, desde la pragmática, tampoco puede ser dejado de lado. Si comprendemos las motivaciones del usuario para acceder a Internet deduciremos lo que más éxito tiene dentro de una oferta amplísima. En este proceso no resulta baladí señalar, como ya hizo Gomis (1991), que el consumo de los medios de comunicación como rito se realiza mayoritariamente en los momentos de ocio, por tanto existe una asociación del consumo de noticias con un pasatiempo para los ratos de asueto. Una motivación que Sánchez Noriega hace extensiva a la generalidad de los mensajes de masas: «El entretenimiento aparece como la principal pretensión de gran parte de los mensajes de masas, sobre todo aquellos que se inscriben dentro del espectáculo o del ocio; pero también la información o las obras culturales, han de ser entretenidas -li- 
geras, divertidas, distraídas- si aspiran a la atención de una audiencia ya acostumbrada a lo fácil y con múltiples ofertas alternativas para elegir la recepción más gratificante» (1997: 328).

Es preciso profundizar en el análisis de los mensajes de Internet desde la recepción y los usos que el consumidor hace de la red dentro de la teoría clásica de los usos y gratificaciones, dando respuestas a cuestiones cómo ¿qué le motiva a navegar?, ¿qué es lo que desea consumir?, ¿qué caracteriza a los productos informativos que tienen más éxito?

Pero además es urgente estudiar cómo se realiza el uso de Internet en los cada vez más extendidos dispositivos móviles. Los nuevos soportes determinan desde aspectos relacionados con el tamaño de la pantalla y las necesidades de compresión de la señal hasta elementos de contenido dada la necesidad de emitir mensajes adecuados a las características de estos terminales: «las peculiaridades físicas del terminal aconsejan que el mensaje sea breve, ya que no es fácil imaginar el mantenimiento de la atención hacia un medio cuyas condiciones de uso implican movilidad y concentración de la recepción en un espacio significativamente pequeño» (Galindo, 2005: 127-143). Se hace preciso ahondar en estos condicionantes y analizar cómo derivan en una profusión de contenidos de infoentretenimiento, más si tenemos en cuenta que cada vez los medios hacen menos un volcado de contenidos de sus versiones tradicionales al nuevo soporte y generan más contenidos elaborados específicamente para la red y los nuevos dispositivos.

\subsection{Las consecuencias de la difusión y el éxito del infoentretenimiento en la red}

Una de las líneas clásicas de estudios sobre medios de comunicación es el análisis de los efectos que éstos provocan en los receptores. Puesto que la tecnología revoluciona la forma de consumir y compartir información es necesario poner al día tanto los planteamientos conceptuales como la aplicación empírica que ayude a conocer mejor la influencia que los nuevos medios y sus contenidos tienen en los distintos sectores sociales. En este campo, hace falta profundizar en las consecuencias que la difusión de informaciones abordadas desde el infoentretenimiento tiene en su audiencia. Un camino que se ha iniciado en el campo de la comunicación política (Tyron, 2008; Towner y Dulio, 2011) pero que está sin desarrollar en muchos otros ámbitos: salud, economía, seguridad, minorías, etc.

\section{Conclusiones}

Atendiendo a la literatura, podemos concluir, en primer lugar, que efectivamente el infoentretenimiento es un fenómeno que tiene su origen en la televisión y que, desde ella, se ha extendido al resto de medios de comunicación. Su inicio viene propiciado por la fuerte competencia existente en el sector que provocó que sus productos se diseñasen buscando satisfacer a un público lo más numero- 
so posible. En la actualidad el infoentretenimiento ha llegado y está muy presente también en Internet y principalmente en las informaciones más consumidas por los receptores.

En términos generales, la investigación sobre infoentretenimiento y, más específicamente, sobre infoentretenimiento en Internet resulta todavía escasa en el ámbito internacional pero lo es especialmente en el ámbito español donde los estudios sobre este fenómeno no superan la veintena, a pesar de que sea una tendencia muy acusada y refrendada por los receptores.

Dada la importancia del infoentretenimiento como fenómeno informativo, se hace necesario profundizar en él y desarrollar investigaciones empíricas que demuestren su grado de expansión cuantitativa y cualitativa en la red y los motivos que provocan que sea el género característico de los productos favoritos del público. Es preciso redoblar el esfuerzo investigador porque asistimos a una revolución en las formas de comunicación e información pero aún es necesaria más literatura que ordene y explique el cómo y el por qué de los procesos que presenciamos, generando una interpretación profunda de la realidad.

Podríamos considerar, a la luz de los estudios analizados, que gran parte de las investigaciones futuras sobre infoentretenimiento en la red podrían apoyarse en las teorías clásicas de la comunicación periodística: la agenda-setting function, el paradigma de usos y gratificaciones o las teorías de los efectos de los medios, dado el desarrollo que estas doctrinas han tenido y su rico marco conceptual. En este sentido resulta adecuado desarrollar estudios que aborden la influencia que la audiencia tiene sobre la agenda en Internet llegando incluso a determinar un cambio en los contenidos de las páginas web informativas más serias incrementando los contenidos próximos al infoentretenimiento. La popularidad de este tipo de contenidos también puede ser analizada desde el punto de vista de la empresa como clave de selección y tratamiento temático para buscar una ansiada pero aún no lograda rentabilidad de las webs informativas.

En otro orden, podríamos señalar la necesidad de definir o clarificar una metodología de análisis significativa para el infoentreteniemiento en Internet, tomando en consideración el agente que crea esos contenidos-bien sean políticos, ciudadanos, líderes de opinión, etc.—, el propio contenido - forma y fondo- - y las repercusiones en los públicos. Sin duda, estamos ante un fenómeno de comunicación clásico que adquiere nuevas formas en Internet y son necesarias nuevas investigaciones que permitan conocer qué implicaciones y efectos tiene para la comunicación y para la democracia occidental.

\section{Referencias}

Anderson, Bonnie M. (2004). News Flash. Journalism, Infotainment, and the Botton-Line Business of Broadcast News. San Francisco: Jossey-Bass. 
Baum, Matthew A. (2002). Sex, lies, and war: How soft news brings foreign policy to the inattentive public. En: American Political Science Review, n ${ }^{\circ}$ 96, 91-109.

Baum, Matthew A. (2003a). Soft news and political knowledge: Evidence of absence or absence of evidence? En: Political Communication, $\mathrm{n}^{\mathrm{o}}$ 20, 173-190.

Baum, Matthew A. (2003b). Soft news goes to war: Public opinion and American foreign policy in the new media age. Princeton: Princeton University Press.

Baum, Matthew A. (2005). Talking the vote: Why presidential candidates hit the talk show circuit. En: American Journal of Political Science, n ${ }^{0} 49,213-234$.

Baum, Matthew A., Jamison, Angela S. (2006). The Oprah effect: How soft news helps inattentive citizens vote consistently. En: Journal of Politics, $\mathrm{n}^{\mathrm{0}}$ 68, 946-959.

Berrocal, Salomé; Abad, Leopoldo; Cebrián, Elena y Pedreira, Elena (2003). El infoentretenimiento televisivo. Las elecciones legislativas de 2000. En: Berrocal, S. (coord.). Comunicación Política en Televisión y Nuevos Medios. Barcelona: Ariel.

Berrocal, Salomé y Cebrián, Elena (2009). El “infoentretenimiento” político televisivo. Un análisis de las primeras intervenciones de Zapatero y Rajoy en “Tengo una pregunta para usted”. En: Textual \& Visual Media, n 2, 42-60.

Berrocal, Salomé y Campos, Eva (2012). El infoentretenimiento político en Internet. Un análisis de los vídeos más vistos en YouTube de José Luis Rodríguez Zapatero y Mariano Rajoy. En: Berrocal, Salomé y Campos, Eva (coords.). La investigación en Periodismo Político en el entorno de los nuevos medios de comunicación. Madrid: Sociedad Española de Periodística.

Berrocal, Salomé; Campos, Eva y Redondo, Marta (2012). El “infoentretenimiento” en Internet. Un análisis del tratamiento político de José Luis Rodríguez Zapatero, Mariano Rajoy, Gaspar Llamazares y Rosa Díez en YouTube. En: Doxa, $\mathrm{n}^{\mathrm{o}} 14$ (Artículo en prensa).

Blumler, Jay G. (ed.) (1992). Television and the Public Interest. London: Sage. Bordieu, Pierre (1997). Sobre la televisión. Barcelona: Anagrama.

Brants, Kees (1998). Who's Afraid of Infotainment? En: European Journal of Communication, $\mathrm{n}^{\mathrm{o}} 13,315-335$.

Cabrera, Ma Ángeles (2009). La interactividad de las audiencias en entornos de convergencia digital. En: Revista Icono 14, n ${ }^{0}$ 14, 164-177.

Canninga, L. (1994). Een vergelijkende analyse van de nieuwscultuur in de buitenlandse berichtgeving op BRTN, VTM, NOS en RTL. En: Media \& Maatschappij, $\mathrm{n}^{\mathrm{o}} 4,91-114$. 
Carpio, José Ángel (2009). El humor en los medios de comunicación. Estudio de Los Guiñoles y sus efectos en las opiniones políticas. Tesis doctoral inédita. Universidad Pontificia de Salamanca.

Cebrián, Elena y Berrocal, Salomé (2010). La irrupción del "infoentretenimiento” en la comunicación política española. Una propuesta para la sistematización de sus formatos televisivos. Texto inédito, pendiente de su publicación por la ACOP, Asociación de Comunicación Política.

Colombo, Furio (1997). Últimas noticias sobre el periodismo. Manual de periodismo internacional. Barcelona: Anagrama.

Chaffee, Steve H. y Metzger, Miriam J. (2001): The End of Mass Communication? En: Mass Communication and Society, $\mathrm{n}^{0} 4,365-379$.

De Fleur, Melvin L. y Ball-Rokeach, Sandra J. (1993). Teorías de la comunicación de masas. Barcelona: Paidós.

Delli Carpini, Michale X. y Williams, Bruce (2001). Let Us Infotain You: Politics in the New Media. En: Bennet, W. L. y Entman R. Mediated politics: communication in the future of democracy. Cambridge: Cambridge University Press, 160-181.

Díaz Arias, R. (2009): Crece el infoentretenimiento y la autopromoción en los informativos. En: http://blogs.telecinco.es/elnautilus/tag/ infoentretenimiento/. [Consultado el 12 de abril de 2010].

Ferré, Carme y Gayá, Catalina (2009). Infoentreteniment i percepción ciutadana de la política: el cas de Polònia. Barcelona: Consell de l'Audiovisual de Catalunya. En: http://www.cac.cat/pfw_files/cma/recerca/estudis_recerca/ Infoentreteniment_i_percepcio_ciutadana_de_la_politica.pdf. [Consultado el 5 de junio de 2012].

Filloux, Frédéric y Gassée, Jean-Louis (2008). The economics of moving from print to online: lose one hundred, get back eight. En: Monday Note. http:// www.mondaynote.com/2008/09/29/the-economics-of-moving-from-print-to-online-ose-one-hundred-get-back-eight. [Consultado el 2 de octubre de 2009].

Franklin, Bob (1997). Newszak and News Media. Londres: Arnold.

Galindo Rubio, Fernando (2005). El audiovisual en la telefonía móvil 3G. Consideraciones formales para una comunicación eficaz. En: Zer, vol. 10, n ${ }^{0} 19$. Leioa: Universidad del País Vasco, Servicio editorial,127-143.

García Avilés, José Alberto (2007). El infoentretenimiento en los informativos líderes de audiencia de la Unión Europea. En: Anàlisi, $\mathrm{n}^{\circ} 35$. Bellaterra: Universitat Autònoma de Barcelona, Servei de Publicacions, 47-63.

Gomis, Lorenzo (1991). Teoría del periodismo. Cómo se forma el presente. Barcelona: Paidós. 
González Requena, Jesús (1988). El discurso televisivo: espectáculo de la posmodernidad. Madrid: Cátedra.

Grabe, Maria et al. (2000). Packaging Television News: The Effects of Tabloid Information Processing and Evaluative Responses. En: Journal of Broadcasting \& Electronic Media, n ${ }^{\circ} 44,581-598$.

Holtz-Bacha, Christina y Norris, Pippa (2001). To entertain, inform and educate: still the role of Public Television. En: Political Communication, $n^{\circ} 18,123-140$.

Labio Bernal, Aurora (2008). Periodismo de entretenimiento: la trivialización de la prensa de referencia. En: Estudios sobre el Mensaje Periodístico, $n^{\circ} 14$, 435-447.

Langer, John (2000). La televisión sensacionalista. Barcelona: Paidós.

Lozano, José Carlos (2004). Espectacularización de la información en noticieros televisivos de Canadá, Estados Unidos y México. En: Diálogo Político, marzo, año XXI. Buenos Aires: Fundación Konrad-Adenauer-Stiftung, 101-116.

Moy, Patricia, Xenos; Michael A. y Hess, Verena K. (2005). Priming Effects of Late-Night Comedy. En: Journal of Public Oppinion Research, nº 18, 198-210.

Noelle-Neuman, Elisabeth (2010). Turbulencias en el clima de opinión. Metodologías de la Teoría de la Espiral del Silencio. En: CIC Cuadernos de Información y Comunicación, $\mathrm{n}^{0}$ 15, 301-318.

Ortells Badenes, Sara (2009). La mercantilización de la información: la nueva era informativa en televisión. Revista Latina de Comunicación Social, $\mathrm{n}^{0} 64$. La Laguna: Universidad de la Laguna. En: http://www.revistalatinacs.org/09/ art/28_827_46_ULEPICC_07/Sara_Ortells.html (FALTA FECHA DE CONSULTA) Postman, Neil (1985). Amusing Ourselves to Death: Public Discourse in the Age of Show Business. Nueva York: Viking Penguin.

Powers, Angela, Kristjandottir, Hildur y Sutton Hal (1994). Competition in Danish Television News. En: Journal of Media Economics, no ${ }^{\circ}$, 21-30.

Prado, Emili (2003). La espectacularización de la realidad. En: Anuario de la televisión. Madrid: GECA, 178-186.

Prior, Markus (2003). Any good news in soft news? The impact of soft news preference on political knowledge. En: Political Communication, ${ }^{0}$ 20, 149171.

Prior, Markus (2005). News vs. entertainment: How increasing media choice widens gaps in political knowledge and turnout. En: American Journal of Political Science, $\mathrm{n}^{\mathrm{0}} 49,577-592$.

Prior, Markus (2007). Post-broadcast democracy: How media choice increases inequality in political involvement and polarizes elections. Cambridge: Cambridge University Press. 
Ramonet, Ignacio (1999). La tiranía de la comunicación. Madrid: Debate.

Roca, Genís (2009). La convergencia de los medios y la guerra de las audiencias. En: Quaderns del CAC, $\mathrm{n}^{0}$ 31-32, 101-104.

Sampedro, Víctor y Valhondo, José Luis (2012). L'infosatira televisiva e i suoi effetti. En: Comunicazione Politica, año XII, nº 1, 43-56.

Sánchez-Tabernero, Alfonso (2008). Los contenidos de los medios de comunicación. Calidad, rentabilidad y competencia. Barcelona: Ediciones Deusto.

Sánchez Noriega, José Luis (1997). Crítica de la seducción mediática. Madrid: Tecnos.

Sartori, Giovanni (1998). Homo videns. La sociedad teledirigida. Madrid: Santillana.

Sparks, Collin y Tulloch, John (coords.) (2000). Tabloid Tales: Global Debates over Media Standards. Maryland: Rowman and Littlefield.

Stockwell, Stephen (2004). Reconsidering the Fourth Estate. En: Actas de la Australian Political Studies Association. Adelaida: University of Adelaida.

Taniguchi, M. (2011). The electoral consequences of candidate appearances on soft news programs. En: Political Communication, $n^{0} 28,67-86$.

Towner, T. L. y Dulio, A. D. (2011). An experiment of campaign effects during the YouTube election. En: New Media \& Society, $n^{0}$ 4, vol. 13, 626-644.

Tyron, Chuck (2008). Pop Politics: Online Parody Videos, Intertextuality, and Political Participation. En: Popular Communication: The International Journal of Media and Culture, vol. 6, 209-213.

Valhondo, José Luís (2011). Sátira televisiva y democracia en España. La popularización de la información política a través de la sátira. Barcelona: Editorial UOC.

\section{Referencia de este artículo:}

Berrocal Gonzalo, Salomé, Redondo García, Marta y Campos Domínguez, Eva (2012). Una aproximación al estudio del infoentretenimiento en Internet: origen, desarrollo y perspectivas futuras. En: adComunica. Revista Científica de Estrategias, Tendencias e Innovación en Comunicación, $\mathrm{n}^{0} 4$. Castellón: Asociación para el Desarrollo de la Comunicación adComunica, Universidad Complutense de Madrid y Universitat Jaume I, 63-79. DOI: http://dx.doi.org/10.6035/21740992.2012 .4 .5 